\title{
EMERGÊNCIA DOS “CONDOMÍNIOS-CLUBE” NA ZONA SUL DE NATAL/RN, BRASIL
}

\author{
the emergence of "Club Condominius" in the south of Natal/RN, Brazil
}

Felipe Fernandes de Araújo*

\begin{abstract}
Resumo
Esse trabalho tem o objetivo de discutir o surgimento de uma nova tipologia residencial que vem se disseminando na Zona Sul da cidade de Natal/RN, os chamados condomínios-clube. Sua característica principal é o apelo aos mais diversos itens de lazer, que são utilizados pelos empresários urbanos como forma de criar um novo estilo de vida e um novo produto a ser vendido. O referencial teórico desse trabalho se baseia na abordagem heterodoxa da coordenação espacial realizada por Pedro Abramo. Tal perspectiva vê o espaço urbano como constituído de estoques residenciais que são oferecidos pelos empresários urbanos. De maneira geral, a ordem urbana e a configuração residencial são incertas, porque sofrem transformações oriundas do surgimento de inovações espaciais causadas por empresários urbanos, em busca de lucros suplementares. No caso da Zona Sul de Natal, a construção de importantes eixos viários liga essa parte da cidade ao município vizinho de Parnamirim, que vem sendo alvo do transbordamento do mercado imobiliário de Natal. O ciclo de vida dos estoques residenciais da Zona Sul de Natal modificou-se com o tempo, passando originariamente da moradia em grandes conjuntos habitacionais para a produção de empreendimentos verticais. Atualmente, um novo fenômeno que surge é a disseminação de uma nova tipologia, os condomínios-clube. Por ser um processo recente, no qual os empreendimentos ainda estão em fase de lançamento ou construção, seu estudo será feito através da análise do marketing utilizado pelos empresários urbanos para atrair os consumidores, por meio de panfletos e folders.
\end{abstract}

Palavras-chaves: Ordem urbana, Convenção urbana, Inovação espacial, Condomínios-clube.

\begin{abstract}
This paper aims to discuss the emergence of a new residential typology that has been spreading in the south of Natal / RN, the so-called club condominiums. Its main feature is the appeal to the most diverse recreational items, which are used by urban entrepreneurs as a way to create a new lifestyle and a new product being sold. The theoretical basis of this work is based on the heterodox approach of spatial coordination performed by Pedro Abramo. This perspective sees the urban space as consisting of residential stock that are offered by urban entrepreneurs. In general, the urban order and the residential configuration are uncertain, because they suffer changes arising from the emergence of spatial innovations caused by urban entrepreneurs in search of extra profits. In the case of Southern area of Natal, the construction of major highways connecting this part of town to the neighboring municipality, Parnamirim, that has been targeted to overflow of housing market in Natal. The life cycle of residential stocks in Southern area of Natal changed over time, passing originally from living in large housing states to the production of vertical projects. Currently, a new phenomenon that arises is the spread of a new classification, the club condominiums. Being a recent case in which the enterprises are still in launch phase or construction, the study will be done through the analysis of marketing used by urban entrepreneurs to attract consumers by means of pamphlets and folders.
\end{abstract}

Key words: urban order, Urban convention, Spatial innovation, Club condominiums.

\section{Resumen}

Este documento tiene como objetivo discutir el surgimiento de una nueva tipología residencial que se ha extendido en el sur de Natal / RN, los condominios llamado Club. Su principal característica es la apelación a los artículos de ocio más diversos, que son utilizados por los empresarios urbanos como una forma de crear un nuevo estilo de vida y un nuevo producto que se vende. La base teórica de este trabajo se basa en el enfoque heterodoxo de la coordinación espacial realizada por Pedro Abramo. Esta perspectiva considera el espacio urbano como un conjunto de inventario de viviendas que son ofrecidas por los empresarios urbanos. En general, el orden urbano y el ambiente residencial es incierto, porque sufren cambios derivados de la aparición de las innovaciones de espacio causadas por empresarios urbanos en busca de beneficios extraordinarios. En el caso de la zona sur de Natal, la construcción de carreteras principales que conectan esta zona de la ciudad al vecino municipio de Parnamirim, que ha sido el blanco de la abundancia del mercado inmobiliario de Natal. El ciclo de vida de los inventarios residenciales de la Zona Sur de Natal ha cambiado con el tiempo, desde el principio de la vivienda en grandes alojamientos para la producción de proyectos verticais. En la actualidad, un fenómeno nuevo que se plantea es la propagación de una nueva clasificación, los condominios club. Al ser un caso reciente en que los proyectos se encuentran todavía en fase de lanzamiento o de la construcción, el estudio se llevará a cabo mediante el análisis de marketing utilizadas por los empresarios urbanos para atraer a los consumidores a través de panfletos y folletos.

Palabras clave: Orden urbana, Convención urbana, Innovación espacial, Condominios club.

(*) Mestre em Estudos Urbanos e Regionais pela Universidade Federal do Rio Grande do Norte - Avenida Capitão Mor Gouveia, Cx. Postal: 1524, CEP: 59072-970 - Natal (RN), Brasil. Tel: (+55 84) 88183169 - felipe@cchla.ufrn.br 


\section{INTRODUÇÃO}

Para compreender a emergência dos condomínios-clube, ao longo dos eixos de expansão da Zona Sul de Natal em direção à Parnamirim, será utilizada a abordagem heterodoxa da configuração residencial realizada por Pedro Abramo. Para tanto, faz-se necessário discutir três conceitos fundamentais para o entendimento da ordem urbana: convenção urbana, externalidades de vizinhança e inovação espacial.

A convenção urbana diz respeito à crença partilhada pelos atores urbanos acerca da localização residencial dos diferentes tipos de famílias. A regularidade da configuração residencial é o resultado do surgimento de convenções em torno da ordem espacial. De acordo com Abramo (2007, p. 36), "[...] as grandezas urbanas - isto é, as localizações, os preços, a verticalidade e a densidade populacional - seriam valores mais frequentemente estabelecidos por convenção". No caso da Zona Sul de Natal, observa-se o surgimento de uma convenção em torno de importantes eixos viários que se beneficia da presença de grandes terrenos para disseminar a tipologia do condomínio-clube.

Abramo (2007) parte da ideia de que as famílias buscam localizar-se junto de pessoas de mesma renda, o que torna a externalidade de vizinhança fundamental para a compreensão da escolha residencial. Assim, as escolhas dos indivíduos se baseiam na posição espacial que cada tipo de família ocupa. Segundo Abramo (2001, s.p), “A relativa homogeneidade social e econômica desses moradores promove o surgimento de uma externalidade de vizinhança que é valorada positivamente pelas famílias".

O conceito de inovação espacial está associado à busca de ganhos suplementares por parte dos empresários urbanos, criando novas localizações e/ou novos produtos e modificando incessantemente a configuração residencial, originando uma ordem urbana caleidoscópica (ABRAMO, 2007).

Esses três conceitos serão discutidos de maneira mais aprofundada e será mostrada a sua relação com a ordem urbana e a dinâmica espacial de maneira geral. Posteriormente, será feita uma leitura do caso da Zona Sul de Natal com base nessa discussão teórica.

\section{CONVENÇÃO URBANA E ORDEM URBANA CALEIDOSCÓPICA}

De acordo com Abramo (2007), a ordem urbana está inserida em um contexto de incerteza (ordem caleidoscópica), oriunda do surgimento de inovações espaciais que modificam tanto os estoques residenciais quanto a população que se movimenta em busca de externalidades de vizinhança. Devido a essa incerteza, a convenção tem o papel de servir como referência sobre a situação futura, permitindo que os agentes do mercado residencial possam tomar decisões. "A convenção urbana seria uma opinião convencional, uma crença compartilhada pelos atores urbanos sobre a localização residencial (virtual) dos diferentes tipos de família" (ABRAMO, 2007, p. 127).

Como a configuração residencial futura é incerta, os participantes buscam orientação com aqueles que julgam mais adequados, melhor informados, ou seja, os empresários urbanos, supondo que eles têm indicação sobre a localização dos diferentes tipos de família. Portanto, a convenção surge de um movimento de opiniões entrecruzadas relativas às antecipações de localização (ABRAMO, 2007).

A convenção urbana sinalizará a localização que os capitalistas devem escolher para oferecerem bens residenciais, assim como as características destes bens. De fato, ela é uma crença referente ao tipo de família que, supostamente, vai se instalar numa determinada localização (externalidade de vizinhança), conforme as inovações espaciais (diferenciações do bem-moradia) propostas pelos capitalistas (ABRAMO, 2001, s.p.).

Abramo (2007) deixa claro que o papel dos comportamentos imitativos é fundamental para o surgimento, permanência ou fracasso de uma convenção. São eles que permitem a "amplificação de uma percepção individual em um processo de encadeamento de antecipações cruzadas (contágio)" 
(ABRAMO, 2007, p. 125). Dessa forma, os participantes do mercado imobiliário encontram uma "representação comum da estrutura residencial futura que os ajudará a se coordenar em termos espaciais" (ABRAMO, 2007, p. 138). Como as famílias de um mesmo tipo de renda buscam convergir suas escolhas para determinada localização, imitar a decisão de outras famílias garante a esperada externalidade de vizinhança. Assim, a partir do momento em que essa crença se torna partilhada pelos participantes do mercado residencial, a convenção produz um comportamento repetitivo nas escolhas de localização.

A sucessão de diversas convenções ao longo do tempo permite definir o que Abramo (2007) aponta como ciclo de vida das localizações urbanas, que representa "a história dos estoques residenciais" em determinada localização, caracterizada a partir do estoque residencial e da externalidade de vizinhança em dado momento. O ciclo de vida de uma localização é composto por uma sucessão de fases durante as quais tais características seriam relativamente constantes. Assim, uma determinada localização materializa as diversas convenções a que foi submetida ao longo do tempo. Dessa forma, tal abordagem propicia relacionar a rigidez do espaço construído (estoque imobiliário) e a fluidez da externalidade de vizinhança (mobilidade residencial) (ABRAMO, 2001).

A sucessão das convenções promove tanto modificações físicas quanto socioespaciais na estrutura intraurbana, formando a imagem de "um mosaico de externalidades em constante mutação: a de uma ordem residencial caleidoscópica" (ABRAMO, 2007, p. 294). Quando a estrutura residencial consegue conservar seu perfil de maneira estável, significa que a convenção urbana conseguiu coordenar as ações dos empresários urbanos. Por outro lado, quando há transformações nas características físicas e/ou nas externalidades de vizinhança da área-localização, as crenças relacionadas à determinada área-localização passam por transições (ABRAMO, 2007).

Conclui-se, portanto, que a convenção urbana é temporária e é oriunda da inovação que os empresários urbanos buscam introduzir constantemente. Devido a essas ações, a ordem urbana é permanentemente dinâmica e "a linha que separa a ordem e a desordem é bastante tênue" (ABRAMO, 2007, p. 143). Para compreender essa sutil relação, é preciso aprofundar a compreensão sobre o papel dos empresários urbanos na configuração residencial.

\section{INOVAÇÃO ESPACIAL E DINÂMICA ESPACIAL}

De acordo com Schumpeter (1984), a constituição do capital compreende constantes inovações tecnológicas e organizacionais no âmbito do processo de produção capitalista, assegurando a reprodução de mercadorias e das relações sociais que nele estão inseridas. A implantação constante de novos sistemas de produção emprega o processo de "destruição criativa" sempre que necessita conquistar novos mercados, lançar novos produtos ou apresentar novas soluções. Segundo Harvey (1996), a acumulação de capital e a expansão territorial constituem a lógica da "destruição criativa". No caso do mercado residencial, os empresários urbanos promovem a destruição de uma paisagem anterior e a modificam, na busca por lucros excepcionais, por meio da inovação espacial.

Com relação à ordem urbana, Abramo (2007) chama a atenção para o fato de que os movimentos das convenções urbanas geralmente resultam da manifestação das inovações espaciais, porém também podem significar a difusão geográfica das mesmas inovações: "É a conjunção de inovações - bem como suas imitações - ao mesmo tempo geradora de ordem e de desordem residencial, que denomino dinâmica espacial" (ABRAMO, 2007, p. 294). De acordo com o autor, a dinâmica espacial é oriunda de um duplo movimento de homogeneização e de diferenciação. O primeiro é fruto da ação de empresários urbanos que "consiste em imitar antigas inovações espaciais praticadas alhures" (ABRAMO, 2007, p. 307), levando a uma homogeneização dos estoques; o segundo é proveniente daquele "tipo verdadeiramente schumpeteriano, que empreendem acima de tudo novas diferenciações dentro de uma mesma localidade residencial" (ABRAMO, 2007, p.307), originando uma diferenciação dos estoques. 
A inovação espacial produz uma depreciação "fictícia" dos estoques passados, uma vez que a diferenciação nas características do produto-habitação induz mudanças nas preferências dos consumidores, gerando uma espécie de "efeito de moda graças ao qual os imóveis, quando envelhecem, perdem a capacidade concorrencial" (ABRAMO, 2007, p. 81). Dessa forma, a inovação-diferenciação confere aos empresários schumpeterianos a possibilidade de impor uma margem de ganho ao mercado da demanda.

Apesar da importância da estratégia da inovação, Abramo (2007) destaca que não se deve desassociar a dimensão espacial do produto-habitação, uma vez que está diretamente atrelada à questão da localização. Devido ao fato de ser um bem imóvel e de alta durabilidade, a diferenciação do produto se realiza por meio de deslocamentos espaciais da demanda residencial.

De fato, quando as famílias decidem consumir (comprar) bem moradia, raciocinam mais por uma lógica de localização do que pelo produto em si. Como supus que o produto seja definido pela busca de externalidades de vizinhança, a inovação urbana só poderá ser definida com base em uma nova oferta de localização que possa atrair tipos de famílias que, a princípio, tenderiam a se transferir para outro local. Assim sendo, as diferenciações do produto habitação serão utilizadas mais frequentemente para propor novas localizações que possam reunir famílias de um tipo particular e produzir uma certa externalidade de vizinhança em outro local (ABRAMO, 2007, p. 84).

Ao gerar uma diferenciação do produto-habitação e impor uma margem de ganho, gera-se também uma valorização da localização convencionada em relação à estrutura residencial anterior (depreciação "fictícia" dos estoques passados), levando as famílias a acreditarem que a crença na convenção se confirmou. Tal efeito de valorização é discutido por Abramo (2007, p. 157-158) como responsável pela "manutenção do caráter segmentado das proposições de localização residencial em termos econômico-espaciais", uma vez que impede a entrada de famílias com status social mais baixo do que a convenção propõe. Em suma, a estratégia de inovação visa atender preferencialmente às famílias de maior poder aquisitivo: "a oferta capitalista de residências estabelecerá uma estratégia de escalonamento de inovações datadas: quanto mais alto o rendimento das famílias em jogo, mais recente será a inovação" (ABRAMO, 2007, p. 308).

Para Abramo (2007), o movimento da população em busca de externalidades de vizinhança provoca mudanças nas zonas residenciais da cidade como um todo. Tal processo pode ser melhor entendido a partir da ideia de uma espiral do mercado imobiliário. De maneira geral, as famílias que se mudam para zonas de renda superior deixam para trás estoques que serão ocupados por famílias de renda inferior, que, "por seu turno, deixarão atrás delas um vazio que provocará novos deslocamentos e assim por diante" (p. 299). Prosseguindo com este raciocínio, vê-se que a inovação espacial pode modificar a externalidade de vizinhança de toda a ordem urbana.

Nos dois capítulos a seguir, será utilizada tal discussão teórica para realizar uma leitura da dinâmica espacial da Zona Sul da cidade de Natal. Primeiro será feito um breve histórico sobre os ciclos de vida de tal área-localização e sua expansão urbana. Em seguida, será enfatizado o surgimento de uma inovação espacial que vem se disseminando em Natal e no município vizinho de Parnamirim, os chamados condomínios-clube.

\section{O PROCESSO DE EXPANSÃO URBANA DE NATAL/RN EM DIREÇÃO Á PARNAMIRIM}

Neste breve histórico sobre a dinâmica espacial da Zona Sul de Natal, destacar-se-á o processo de expansão da cidade em direção ao município de Parnamirim, que passa a se intensificar por volta da década de 1990. Neste período, surgem novos centros associados aos principais eixos viários da cidade, como a Avenida Senador Salgado Filho (BR-101), responsável por comportar o fluxo diário dos moradores de Parnamirim que trabalham em Natal. Ao longo dessa avenida, mais recentemente, foi construído o Complexo Viário do Quarto Centenário, que interliga duas grandes 
avenidas, Prudente de Morais e Salgado Filho, através da Avenida Lima e Silva. Inaugurada em 1999, é uma das maiores obras viárias que a cidade possui (FURTADO, 2007).

Conforme Furtado (2007), com relação à atividade comercial ao longo de tal eixo, observa-se um incipiente crescimento até início dos anos 1990, elevando-se consideravelmente a partir de então, a partir da inauguração de dois grandes shoppings centers na BR-101 e com o processo de desconcentração de algumas atividades em direção à Zona Sul da cidade. Às margens desse eixo, localizam-se alguns dos maiores conjuntos habitacionais da cidade, como Cidade Satélite, Mirassol, Candelária e Neópolis, construídos pelo BNH nas décadas de 1970 e 1980 . Com relação ao ciclo de vida da Zona Sul de Natal, observa-se nesse período a primeira fase da sua ocupação, por meio de conjuntos habitacionais voltados à classe média da população. Com base em Abramo (2007), compreende-se que a homogeneidade oriunda de tal externalidade de vizinhança foi fundamental para a posterior valorização dessa área-localização. De acordo com Furtado (2007), as moradias em conjuntos habitacionais só começaram a perder valor quando a população local incorporou a "cultura" do apartamento. Em outras palavras, o surgimento de uma inovação espacial provocou a depreciação "fictícia" dos estoques nos conjuntos habitacionais e a consolidação de uma nova convenção urbana.

Tem-se, portanto, na década de 1990, um novo momento no ciclo de vida da Zona Sul de Natal: a construção de empreendimentos verticais. Para Costa (2000), o período correspondente à década de 1990 caracterizou-se por ser o de maior crescimento vertical na cidade, concentrando 367 construções ou $67 \%$ de todas as construções verticais realizadas em Natal, sendo $92 \%$ de prédios residenciais. $\mathrm{O}$ autor afirma que o aumento da demanda por habitações em edifícios verticais em Natal está relacionado à criminalidade urbana e ao prestígio social que esse tipo de residência desfruta entre as camadas de maior poder aquisitivo. Como vimos, a ação dos empresários urbanos consiste na criação de novas preferências dos consumidores, modificando o imaginário da população. Sobre esse aspecto, Costa (2000, p. 293-294) é esclarecedor: "Esse imaginário da moradia vertical é criado pelos agentes imobiliários através da mídia, para a qual o apartamento em edifício é sinônimo de tranqüilidade, conforto, segurança, lazer, área verde, bela paisagem, qualidade de vida etc.”.

No início da década de 1990, a maioria dos lançamentos imobiliários se localizava na Zona Sul, quando a cidade começava a se expandir em direção ao município vizinho, Parnamirim (NOBRE, 2001). Segundo Clementino e Souza (2009), há um transbordamento do mercado imobiliário da região sul de Natal para Parnamirim. De acordo com o IBGE (2010), no ano 2000, a cidade de Natal possuía 14 mil unidades de apartamento, o que representava $7 \%$ do total de habitações. No último censo, esse número passou para 28 mil. Os apartamentos agora representam $12 \%$ do total. A vizinha Parnamirim acompanha o crescimento da capital. No ano 2000, o município possuía 3 mil unidades de apartamento. O último censo revelou que esse número subiu para 7 mil. De acordo com Clementino e Souza (2009), o apartamento representa o espaço de moradia preferencial da elite na Região Metropolitana de Natal.

Com base nos dados de licenciamentos da Prefeitura de Parnamirim (2010), observa-se que houve um aumento significativo no número de unidades licenciadas entre 2008 e 2010 , o que indica o aquecimento do setor imobiliário no município. Além disso, em 2010, o total de unidades multifamiliares (apartamentos) representou aproximadamente $95 \%$ do total de unidades licenciadas no ano, conforme pode ser visto na tabela 1. 
Tabela 1: Unidades habitacionais licenciadas entre 2008 e 2010 em Parnamirim

\begin{tabular}{l|c|c} 
ANO & $\begin{array}{c}\text { UNIDADES HABITACIONAIS LI- } \\
\text { CENCIADAS }\end{array}$ & MULTIFAMILIARES \\
\hline 2008 & 904 & 337 \\
\hline 2009 & 5354 & 4474 \\
\hline 2010 & 12445 & 11799
\end{tabular}

Fonte: Dados da Prefeitura Municipal de Parnamirim, 2010.

De acordo com Marta Turra (2003), ao estudar a importância dos financiamentos habitacionais da Caixa Econômica Federal, no período de 1995 a 2002, para a expansão da Grande Natal, dois bairros de Parnamirim foram os mais impactados com a corrida imobiliária para além dos limites administrativos do município de Natal: Nova Parnamirim e Emaús. Turra (2003, p. 94) desvenda um dos motivos para tal expansão: "Em relação às duas áreas (Nova Parnamirim e Emaús) cabe acrescentar que as mesmas não são cobertas pelo Plano Diretor de Natal, o que permite inferir que este fato pode ser considerado um atrativo extra para os investimentos em moradia na região".

Além disso, a ligação entre Natal e Parnamirim através da BR-101 e da Avenida Ayrton Senna, bem como a ligação dessas duas vias entre si pelas avenidas Abel Cabral e Maria Lacerda Montenegro, definiram um "novo quadrilátero dos investimentos e negócios imobiliários na Grande Natal" (TURRA, 2003, p. 107) e propiciou a instalação de serviços especializados, como de saúde, educação, gêneros alimentícios e de material de construção. Pelo fato dos bairros de Nova Parnamirim e Emaús serem limítrofes com o município de Natal e cortados por tais eixos viários, os investimentos imobiliários foram mais intensos nesses bairros. "Em toda essa extensão, predomina a construção de edifícios residenciais, representando uma maior tendência de urbanização vertical quanto maior for a proximidade da divisa entre os municípios de Natal e Parnamirim" (TURRA, 2003, p. 112). Atualmente, outro eixo viário de expansão que irá representar uma importante ligação entre os dois municípios é o prolongamento da Avenida Prudente de Morais, que está sendo construído e que pode vir a significar uma nova frente de abertura para o mercado imobiliário.

\section{SURGIMENTO DOS CONDOMÍNIOS-CLUBE AO LONGO DOS EIXOS DE EXPANSÃO DA CIDADE}

De acordo com Abramo (2007), quando se dão conta de que, em certos locais, passa a vigorar uma nova crença concernente à configuração futura das residências, e se os estoques reais forem significativamente diferentes dos propostos pela nova convenção urbana, os empresários decidem produzir residências em tal área-localização. No caso de Natal, a Zona Sul da cidade tornou-se um lugar privilegiado de investimentos em infraestrutura, bem como em habitação para a classe média da cidade. Os empresários urbanos utilizam em suas propagandas a localização dos empreendimentos na Zona Sul como forma de atrativo para os consumidores, inclusive no caso dos empreendimentos que se localizam em Parnamirim, chamada de Zona Sul da Região Metropolitana de Natal.

O fenômeno mais recente com relação ao ciclo de vida da Zona Sul de Natal é o advento dos condomínios-clube. É importante destacar que, por ser um fenômeno bastante atual, todos os empreendimentos dessa tipologia estão em fase de lançamento ou construção e sua localização se dá justamente ao longo dos eixos viários de expansão entre Natal e Parnamirim, conforme mostra a Figura 1.

Abramo (2001), com base na ideia de "ciclo puro" de Kalecki, destaca que a produção do estoque imobiliário se realiza no tempo (cronológico), daí que as mudanças reais só vão interferir no nível da estrutura residencial após um tempo médio de produção. Nesse sentido, no caso dos condomínios-clube em Natal, embora ainda estejam em fase de lançamento ou construção, pode-se 
perceber que há uma aproximação do ponto de encontro entre o estoque real e a representação veiculada pela convenção urbana. Somente após tal encontro haverá de fato uma mudança no estoque residencial e nas externalidades de vizinhança. De qualquer forma, esse período de transição não impede que seja feita uma tentativa de compreensão desse novo momento por que passa o ciclo de vida da Zona Sul de Natal, principalmente através do marketing utilizado pelos empresários urbanos.

A definição de condomínio-clube está associada aos empreendimentos que possuem grandes áreas de lazer, o que implica na necessidade de terrenos de grande extensão. Dessa forma, privilegiam-se as áreas comuns externas em detrimento do tamanho dos apartamentos, que apresentam espaço interno reduzido (SAMPAIO, 2009; CAMPOS, 2007). Essa tipologia originou-se na década de 1980 nos empreendimentos construídos na Barra da Tijuca, no Rio de Janeiro, e tem sua imagem associada à possibilidade de ter acesso ao lazer sem a necessidade de enfrentar a violência e os perigos da cidade (SAMPAIO, 2009).
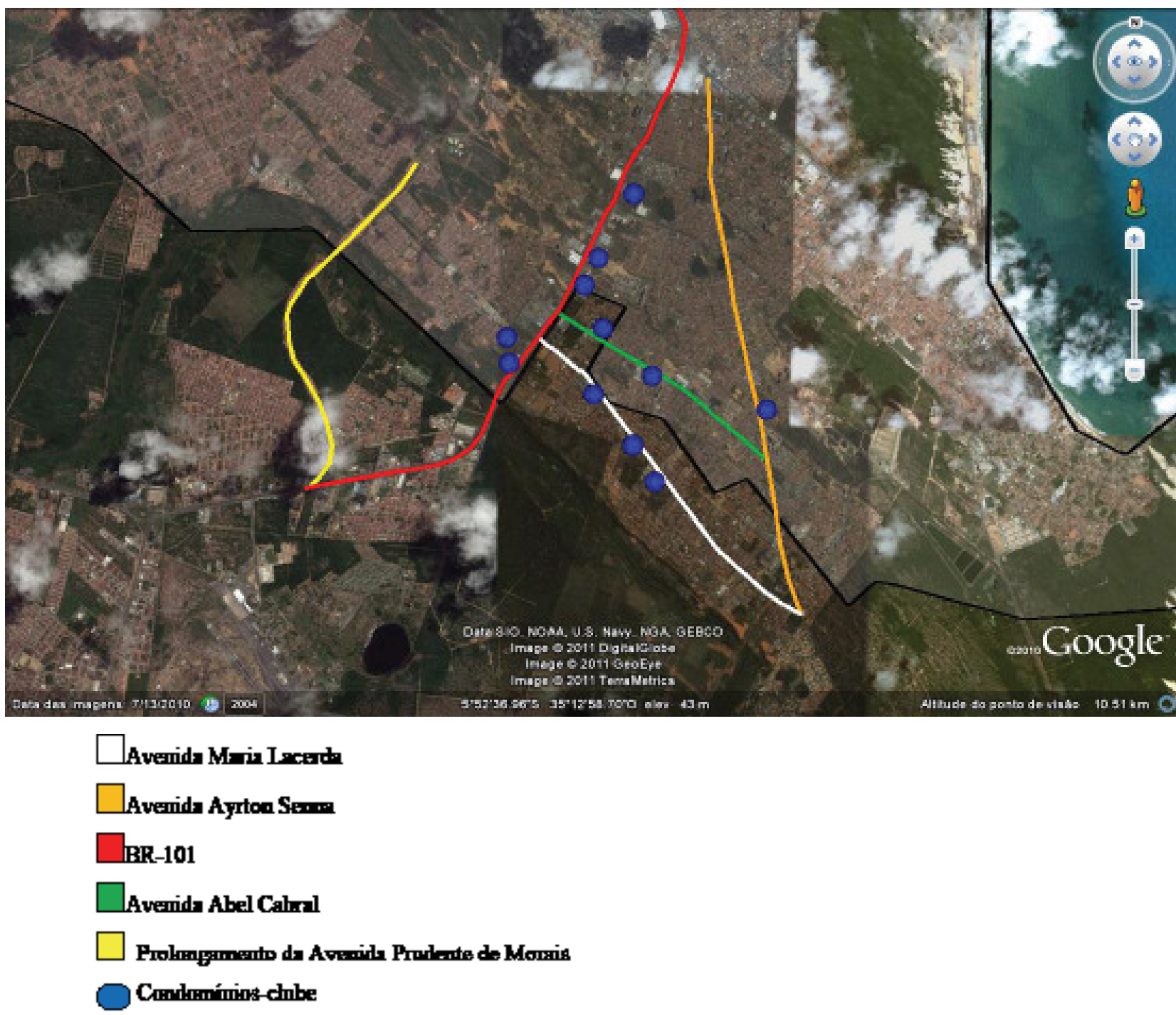

Figura 1 - Localização dos condomínios-clube ao longo dos eixos de expansão de Natal em direção à Parnamirim. Fonte: Elaborado pelo autor com base na imagem do Google Earth (2011)

De acordo com o referencial teórico adotado, pode-se observar que a inovação criada pelos empresários urbanos objetiva tornar-se uma convenção ao longo dos eixos viários de expansão de Natal em direção a Parnamirim. Tal área-localização apresenta significativa quantidade de terrenos de grande extensão, fundamentais para a construção de empreendimentos do tipo condomínio-clube. Como forma de ilustrar, pode-se citar os exemplos dos empreendimentos "Novo Stillo Home Club", 
no qual o terreno chega a $20.000 \mathrm{~m}^{2}$; "Central Park Condomínio Clube", com terreno de $60.000 \mathrm{~m}^{2}$; "Vila Park" com terreno de $70.000 \mathrm{~m}^{2}$; "L'acqua Condominium Clube", em que o terreno tem aproximadamente $43.000 \mathrm{~m}^{2}$.

Para Nobre (2001), na década de 1990, em Natal, há uma inovação no que se refere às campanhas publicitárias, introduzindo um elemento capaz de gerar lucros excepcionais à produção imobiliária: o acesso a uma bela vista. A paisagem torna-se um ativo para os empresários urbanos atraírem novos consumidores:

[...] as campanhas publicitárias realizadas antes da construção dos edifícios são mais elaboradas, uma vez que, não estando pronto o produto, a necessidade de despertar o interesse do comprador torna-se mais intensa. Entende-se que nesse contexto as menções à paisagem ocorram com maior frequência, tendo em vista o poder de sedução nela implícito (NOBRE, 2001, p. 98).

No caso dos condomínios-clube, a área de lazer cada vez mais assume posição de destaque nos informes publicitários do mercado imobiliário residencial. $\mathrm{O}$ espaço comum abrange diversos itens de lazer, como sala de ginástica, piscinas, quadras poliesportivas, lan house, brinquedoteca, salão de jogos, espaço gourmet, redário (praça de descanso destinada para armar rede, hábito comum no nordeste brasileiro). A tabela abaixo ilustra alguns empreendimentos localizados na área de estudo e a maneira pelas quais o marketing utiliza os itens de lazer para atrair os consumidores:

Tabela 2: O lazer no marketing imobiliário

\begin{tabular}{l|c}
\multicolumn{1}{c|}{ NOME DO EMPREENDIMENTO } & DISCURSO DOS EMPRESÁRIOS URBANOS \\
\hline CENTRAL PARK CONDOMÍNIO CLUBE & "Amplo parque aquático e mais de 30 opções de lazer e conforto" \\
\hline L'ÁCQUA CONDOMINIUM CLUBE & "Tudo o que sua família sempre quis: mais de 40 itens de lazer, diver- \\
são garantida"
\end{tabular}

Fonte: Realizado com base em panfletos publicitários

De acordo com Sampaio (2009), para criar uma associação ao status, é comum que o marketing adote termos como clube, parque ou jardim. Outra estratégia utilizada pelos empresários urbanos é o emprego de línguas estrangeiras na denominação dos edifícios. Loureiro e Amorim (2005) dão alguns exemplos: "Villa com duplo "l", distingue e distancia das conotações de vila popular e aproxima das villas italianas; residence, diferencia de residencial, também associado à moradia popular". De acordo com D’Ottaviano (2010, p. 183), sobre a propaganda de lançamento de condomínios fechados na Região Metropolitana em São Paulo, "o discurso da qualidade de vida, da oferta de lazer, conforto e estilo de vida está mais presente do que o discurso da segurança".

Enfim, compreende-se que as estratégias dos empresários urbanos se utilizam da recriação constante de um ideal de morar, introduzindo novos produtos que satisfaçam as expectativas dos consumidores e criando novas necessidades (LOUREIRO E AMORIM, 2005).

\section{CONSIDERAÇÕES FINAIS}

A ordem urbana é incerta e dinâmica, refletindo o movimento inter e intraurbano da população que migra com o intuito de usufruir de externalidades de vizinhança, bem como as transformações nos estoques residenciais das áreas-localizações. Tal ordem é fruto do processo incessante de inova- 
ção espacial criada pelos empresários urbanos. Para tentar referenciar a ação dos atores urbanos no mercado residencial, surgem convenções urbanas que expressam a crença acerca da localização dos diferentes tipos de famílias. Tais convenções correspondem ao elemento de coordenação espacial dos atores no mercado residencial.

Uma área-localização específica materializa as diversas convenções por que passou ao longo do tempo. Cada convenção possui um ciclo de vida no qual as características dos estoques e da população são estáveis. Quando há transformações nessas características, as convenções passam por um período de transição.

As inovações implantadas propiciam uma diferenciação no bem-moradia, em busca de alguma característica exclusiva ou peculiar que proporcione lucros extras para os empresários urbanos. Isso se dá porque ocorre uma depreciação "fictícia" dos imóveis antigos em relação aos que foram criados mais recentemente, que se tornam mais valorizados. Por outro lado, a difusão dessa estratégia de diferenciação pode dar origem a uma configuração em que os estoques residenciais passem a apresentar características semelhantes.

No caso da cidade de Natal, observa-se que a estratégia de construção de uma nova tipologia residencial, os condomínios-clube, disseminou-se ao longo de importantes eixos viários da Zona Sul, em direção ao município de Parnamirim, constituindo-se numa nova tendência. A principal característica de tais empreendimentos é a grande diversidade de itens de lazer existentes nas áreas comuns, com o intuito de representar qualidade de vida, conforto e tranquilidade. Aproveitando-se de grandes glebas de terra, da infraestrutura de transporte construída e da localização de grande gama de serviços, tal área-localização constitui-se atualmente em um dos alvos preferidos dos empresários urbanos. A população que irá residir nos condomínios-clube compreende uma parcela relativamente privilegiada da cidade, que encontra a externalidade de vizinhança desejada e a valorização do estoque residencial oriunda do mais novo movimento da dinâmica espacial da Zona Sul de Natal.

\section{AGRADECIMENTOS}

Agradeço ao professor Márcio Moraes Valença pelos comentários, críticas e sugestões.

\section{REFERÊNCIA BIBLIOGRÁFICA}

ABRAMO, Pedro. Dinâmica espacial e instabilidade do mercado imobiliário: a ordem-desordem urbana. Belo Horizonte, 2001. Disponível em: http://www.eg.fjp.mg.gov.br/gestaourbana/arquivos/modulo09/ mod9arq7.html. Acesso em: 12 jul. 2011.

ABRAMO, Pedro. A cidade caleidoscópica: coordenação espacial e convenção urbana: uma perspectiva heterodoxa para a economia urbana. São Paulo: Bertrand Brasil, 2007.

CAMPOS, Iberê M. A epidemia dos Condomínios-Clubes. Seminário do Fórum da Construção, São Paulo, 2007. Disponível em: http://www.forumdaconstrucao.com.br/conteudo.php?a $=33 \& C o d=61$. Acesso em 29 jul. 2011.

CLEMENTINO, Maria do Livramento Miranda; SOUZA, Maria Ângela de Almeida (Org.). Como andam Natal e Recife. Rio de Janeiro: Letra Capital:Observatório das Metrópoles, 2009.

COSTA, Ademir Araújo da. A verticalização e as transformações do espaço urbano de Natal/RN. Tese (Doutorado no Programa de Pós-Graduação em Geografia) - Universidade Federal do Rio de Janeiro, Natal, 2000.

D’OTtaViano, Maria Camila Loffredo. Condomínios fechados na Região Metropolitana de São Paulo: fim do modelo centro rico versus periferia pobre? Tese (Doutorado no Programa de Pós-Graduação em Arquitetura e Urbanismo) - Universidade de São Paulo, São Paulo, 2010.

FURTADO, Edna Maria.O turismo na capital potiguar: visões sobre o espaço urbano de Natal/RN. Mercator: Revista de Geografia da UFC, ano 06, número 11, 2007. 
HARVEY, David. Condição Pós-Moderna: uma pesquisa sobre as origens da mudança cultural. São Paulo: Edições Loyola, 1996.

IBGE. Instituto Brasileiro de Geografia e Estatística. Censo 2010. Disponível em: http://www.ibge.com. br. Acesso em: 20 ago. 2011.

SCHUMPETER, Joseph Alois. Capitalismo, socialismo e democracia. Rio de Janeiro: Zahar, 1984.

TURRA, Marta. Estado, expansão urbana e acumulação de capital: os financiamentos da CEF em Nova Parnamirim e Emaús (1995-2002). Dissertação (Mestrado no Programa de Pós-Graduação em Geografia) - Universidade Federal do Rio Grande do Norte, 2003.

LOUREIRO, Cláudia; AMORIM, Luiz. Dize-me teu nome, tua altura e onde moras e te direi quem és: estratégias de marketing e a criação da casa ideal. 2005. Disponível em: http://www.vitruvius.com.br/ arquitextos/arq000/esp281.asp. Acesso em: 24 jul. 2011.

NOBRE, Paulo. Entre o cartão-postal e a cidade real: um estudo sobre paisagem e produção imobiliária em Natal/RN. Dissertação (Mestrado no Programa de Pós-Graduação em Arquitetura e Urbanismo) - Universidade Federal do Rio Grande do Norte, 2001.

PARNAMIRIM. Secretaria Municipal do Meio Ambiente e do Desenvolvimento Urbano. Dados de Licenciamento do município de Parnamirim entre os anos de 2008 e 2010. Disponível em meio digital para a base de pesquisa Unidade Interdisciplinar de Estudos sobre Habitação e o Espaço Construído.

SAMPAIO, Giuliana Beatriz Dalfovo do Amaral. Condomínios Verticais Residenciais na cidade de São Paulo (2000-2008): condomínios-clube. Dissertação (Mestrado no Programa de Pós-Graduação em Arquitetura e Urbanismo) - Universidade Presbiteriana Mackenzie, São Paulo, 2009.

Trabalho enviado em maio de 2012 Trabalho aceito em junho de 2012 